\title{
STRATEGY AND LEADERSHIP
}

WITH CONTRIBUTING AUTHOR JALANA MCCASLAND

\section{LEARNING OBJECTIVES}

1. Explain the importance of strategic planning in ambulatory practices

2. Describe the elements of strategic intent

3. Articulate the steps of the strategic planning process

4. Depict the role of leadership and management in the realization of identified strategies

\section{KEY TERMS}

Competition

Strategic Intent

Stakeholders

Core Competency
Strategic Plan

Environmental Analysis

Strategic Alternatives

Psychological Safety

\section{INTRODUCTION}

Strategy development and execution are essential to every organization. Providing a road map for the organization, a strategic plan translates the values, vision, and mission of an organization into action. For organizations to succeed, they must interpret the current landscape and trends, craft and communicate a cogent strategic intent, assess and develop the capacity for change, forge and execute plans with conviction, and continually learn from their actions. For the well-managed ambulatory practice, the creation and implementation of a strategic plan provide essential guidance to successfully navigate the impact of internal and external forces. As the environment for an ambulatory practice is ever-changing, strategy development requires both leadership vision and attention to detail. Because strategic planning is essential to long-term viability, every ambulatory practice can and should engage in it, regardless of the practice's size or organizational structure. 


\section{STRATEGY}

The ambulatory environment demands attention to strategy as competition is fierce, technology is rapidly evolving, and patients demand not only quality care but convenient access and exceptional service as well. A well-managed ambulatory practice understands these challenges and seeks to proactively address them instead of simply reacting to them.

Although a singular term, a strategy - and the planning process to articulate one-is a continuous, iterative process rather than a distinct event. The planning cycle begins with visioning and setting goals, developing objectives and tactics to achieve that vision, monitoring performance, adjusting as needed based on business intelligence, and continuously reflecting and revising the plan. Historically, ambulatory practices used a horizon of 10 years into the future for strategic planning. However, given the uncertainty of today's healthcare environment, the horizon is typically one to three years. Strategic planning is not a final destination but rather an ongoing journey that must be constantly revisited.

\section{Roles and Responsibilities}

Developing a strategy is a continuous process of assessment, learning, and adjustment. Strategy — and the plans that emanate from the development of one-requires a thoughtful approach. The ambulatory practice must create a formal structure for strategic planning, establish or update the organization's strategic intent, and take steps to develop the plan. Developing successful strategies requires the active participation of everyone in the ambulatory practice; however, key stakeholders play an important role in the coordination and oversight for the development and execution of the strategic plan. The roles and responsibilities for strategy development include the governing body and the practice's leaders and managers. The stakeholders incorporate physicians and other clinical leaders, as well as the administrator(s) of the practice.

\section{Governing Body}

The composition of a governing board varies across ambulatory organizations. For many ambulatory practices, the governing body is comprised of the managing partners, who are typically physicians. The administrator may also be a member of the board. The governing body leads the practice's effort in strategy development and planning. Smaller physician practices may be owned and operated by a physician owner or founder who sets the direction for a strategic plan, with input from others within the practice and perhaps with the support of a third-party consultant or advisor. Some ambulatory practices may not have a true governing board but rather an executive group composed of key physician leaders who execute strategy. 
Ambulatory practices owned or operated by a hospital or health system typically fall under the auspices of the facility's board of trustees. The board of trustees resides at the corporate level and is responsible for coordinating the development and approval of the health system's strategic plan. The systemwide plan may include a component focused on the ambulatory enterprise, just as it would for inpatient, skilled nursing, and the other service lines of the health system. For the ambulatory component, the strategic planning process is often delegated to physicians and administrative leaders with ambulatory expertise. They are selected to craft a strategy for the ambulatory enterprise that aligns with the health system's goals.

Regardless of composition, the governing body plays three important roles in the strategy development process: surveillance, capacity building, and stakeholder identification and engagement.

\section{Surveillance}

The governing board sets the overall direction of an organization by establishing its values, vision, and mission. The formation of these strategic intents may only occur once in the history of the organization; however, they may be updated particularly if there is a major change to the organization, such as a merger or an acquisition. On an ongoing basis, the governing board serves a surveillance role. In this position, the board not only identifies and acknowledges opportunities but also serves to challenge assumptions (Orlikoff \& Totten, 2006). Governing boards must balance the need to be good stewards of the organization while at the same time making crucial decisions for future investments (Orlikoff \& Totten, 2006). This corporate-level perspective is important in setting the tone and direction for the strategic plan.

\section{Capacity Building}

Another role the governing body plays in the strategy development and planning process relates to capacity building. The continual assessment of the organization's capabilities and competencies provides insight into the ability of the organization to achieve its desired results. For example, if the ambulatory practice's strategy is to shift the care delivery model to place greater emphasis on prevention and wellness - a population health management strategy - the governing body would need to assess the current capabilities and competencies within the practice to effectively execute the strategy. A successful strategic plan is not only one that inspires and motivates action but one that is also practical and achievable. If the strategic plan needs resources or technology, the governing body must prioritize integrating those resources, or capacity building, within the other needs of the ambulatory practice. 


\section{Stakeholder Identification and Engagement}

The third role of the governing body as it relates to strategy development and planning is identifying and engaging relevant stakeholders. Relevant stakeholders are those committed to the organization's strategic intent and in a position to influence the attainment of the desired results. The board ensures stakeholder input is incorporated into the strategic planning process and that stakeholders' needs and expectations drive the organization's goals. For example, in crafting an ambulatory strategy for a hospital, physician participation in the strategic planning process at the board level as a key stakeholder is essential. The board may also solicit input from key community leaders or other partners or affiliates who can provide an additional external perspective on what the community or region needs. This input is essential in crafting a strategic plan that not only meets the needs of the key practice stakeholders (providers, staff, and patients) but also delivers value to the community.

\section{Ambulatory Practice Leaders}

The input of physicians and other clinicians serving in the practice is key in the development and execution of the strategic plan. Clinical leaders often serve as change leaders or champions to help operationalize the plan. Similarly, ambulatory leaders such as the practice administrator or manager and other key clinical and administrative leaders provide important input as well as help assess the practice's capacity and willingness to adopt the strategic plan.

Larger ambulatory practices or those embedded within hospitals or health systems may have a senior official, such as a vice president or a director of strategy, who manages the strategic planning process. Practices may also engage the services of a third-party consultant to assist with certain aspects of the strategic planning process, specifically as it relates to moderating the planning session; offer intelligence regarding industry trends; or solicit and report on insight gleaned from patients or referral sources. A third party may also be in the best position to interview the practice's personnel and present blinded findings regarding themes and opportunities for improvement.

Every ambulatory practice can engage in strategic planning. However, the strategic planning process is additive to the work of the physicians and leaders who are already busy overseeing daily operations. While the roles and responsibilities may vary depending on the size of the practice and can often be shared between members, the time needed to devote to a strategic planning process should not be underestimated. For this reason, the practice must clearly articulate the roles and responsibilities of the individuals engaged in the strategic planning process. Doing so avoids duplication and makes the best use of the practice's resources. 


\section{Strategic Intent}

Strategic intent is an organization's overarching purpose; it is crucial to determine the alignment of strategy with the mission, vision, and values of the organization. The purpose serves to inform stakeholders of the organization's commitment to its direction and functions as a basis upon which to measure success. As an otolaryngology practice, should we open an ambulatory surgery center? As a multispecialty practice, should we launch a transitional care management clinic? As an ambulatory enterprise of a health system, should we invest in a nurse contact center? What purpose will these strategies serve? Do they align with the practice's values, mission, and vision? These are questions that can best be addressed by understanding strategic intent. Strategies, like enzymes, are catalysts, which lead to a desired outcome or change. Strategies guide behaviors, which, in turn, are used to steer actions and subsequently achieve results.

In The Theory of Business, Peter Drucker suggests that an organization's failure to thrive is not based on doing the wrong things or doing things wrong; rather, he states, failure is related to the "assumptions on which the organization has been built and is being run no longer fit reality" (Drucker, 1994, p. 95). These assumptions, he asserts, "shape an organization's behavior, dictate its decisions about what to do and what not to do, and define what the organization considers meaningful results" (Drucker, 1994, p. 96). Understanding an organization's strategic intent is a fundamental first step in the strategy process.

Values, vision, and mission are the elements that contribute to defining strategic intent (see Figure 2.1). Values are the shared concepts and beliefs the ambulatory practice and its members hold dear; they are the core principles that guide behavior. The vision is a future-oriented statement of the practice's purpose and how the practice wants others to view it. The vision is aspirational and identifies where the organization wants to be in the future. The mission is used to communicate an organization's business today. A mission statement captures the practice's reason for being and reflects the present.

\section{Strategic Plan}

Strategy is the catalyst that makes possible the achievement of desired outcomes, serving to guide behaviors and achieve organizational vision and mission, all while being true to the organizational values. A strategic plan is the result of creating and documenting the organization's strategies. Using the analogy of constructing a building, the organization's strategic intent (values, vision, and mission) serves as the building's blueprint, a guide to the organization's desired results (see Figure 2.2). The strategic plan, a conglomeration of individual strategies designed to achieve the purpose of the organization, supports the building's foundation. Each strategy is then organized 
Strategic Intent
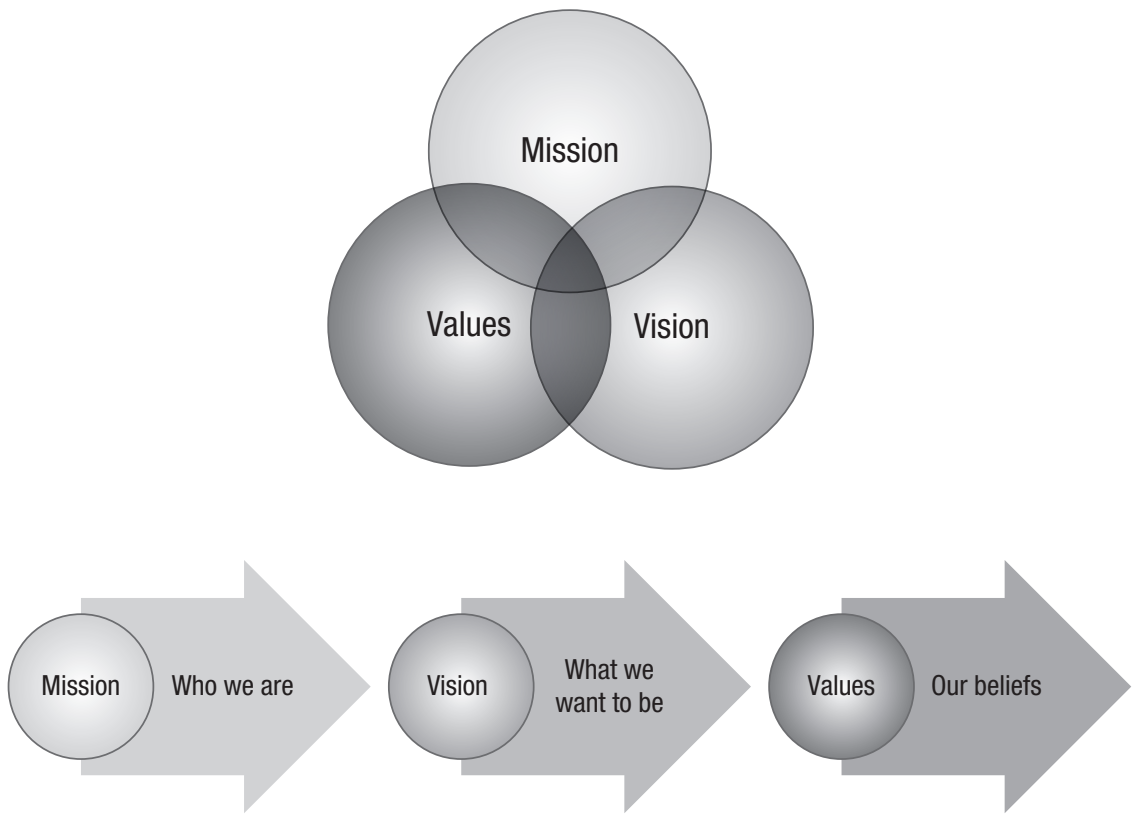

FIGURE 2.1 Strategic intent.

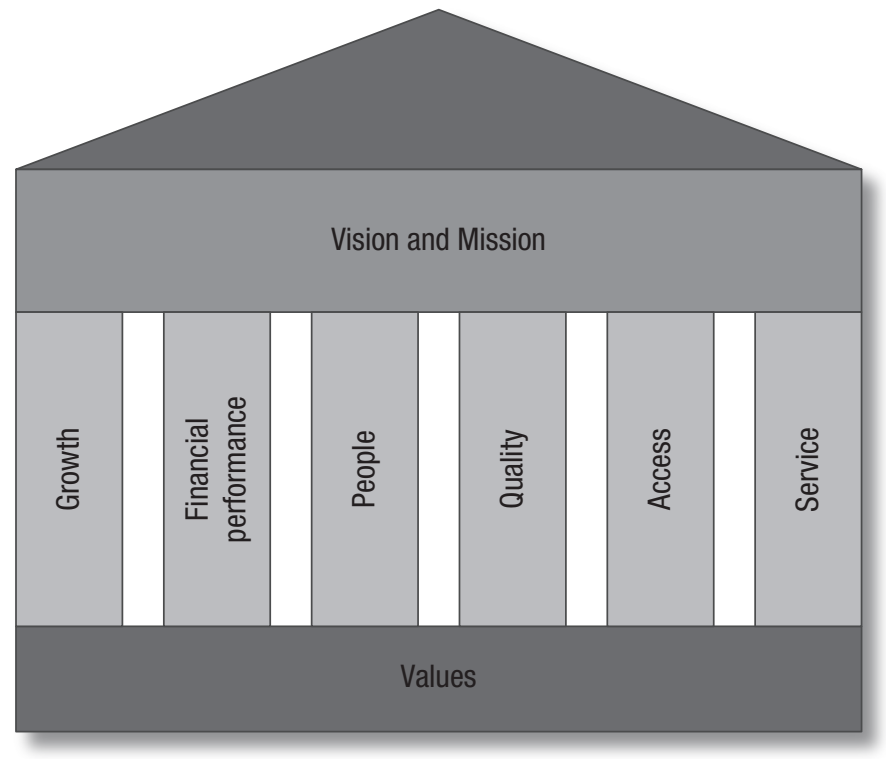

FIGURE 2.2 Strategic pillars.

and the execution coordinated; this provides a framework for action, much like the studs and joists used to frame a building. The alignment of coordinated strategies is referred to as the organization's strategic plan. 
The process of strategic planning allows a practice to maintain one eye on the future-leading — and the other eye on the present-managing-with a purpose and conviction reflective of the organization's values, vision, and mission.

For many ambulatory practices, an effective way to organize this work is to establish pillars based on the organization's strategic intent. For example, recruiting and retaining personnel who support the values, mission, and vision of an ambulatory practice is essential to its success. By creating a "people" pillar, the practice recognizes the importance of its human capital. The strategic plan may include an objective to attract and retain top-performing personnel to the organization. The tactic determined to meet this goal may be to offer and maintain market-competitive compensation and benefits. Actions that may emanate from the tactic are a biannual market compensation review, an employee engagement survey, the formation of a compensation task force, and an analysis of exit interviews from prior periods.

An effective visual cue for stakeholders involved in the strategic planning process - as well as those engaged in it as personnel of the practice-the pillars connect the organization's mission and vision to its stated values. Pillars are unique to each practice and should be derived from the organization's values. Pillars for consideration in an ambulatory practice include people, access, quality, financial performance, growth, and service. The number of pillars should be reasonable; easily communicated to the practice providers, staff, and other stakeholders; and reflective of the practice's strategic intent.

\section{STEPS TO DEVELOP A STRATEGIC PLAN}

The steps to develop a strategic plan, as outlined in Figure 2.3, include conducting the environmental analysis, developing strategic alternatives, creating strategic goals and objectives, creating an action plan, executing the plan, and evaluating progress toward the desired goals. Strategic planning is an iterative process as each strategy is evaluated and adjustments made based on performance or changes to the underlying assumptions based on new data.

\section{Step 1: Conduct an Environmental Analysis}

The environmental analysis is an assessment of an organization's internal capabilities and competencies as well as a reflection on the external landscape. An environmental analysis is not a matter of conjecture or opinion or based solely on subjective input from key stakeholders. While important, stakeholder input is just one component of data collection. Factual data and business intelligence about the internal and external environment provide the foundation for the analysis. A well-managed ambulatory practice relies on an evidence-informed planning process. Using objective tools, appropriately and for the intended purpose, reduces biases, encourages broad-based 


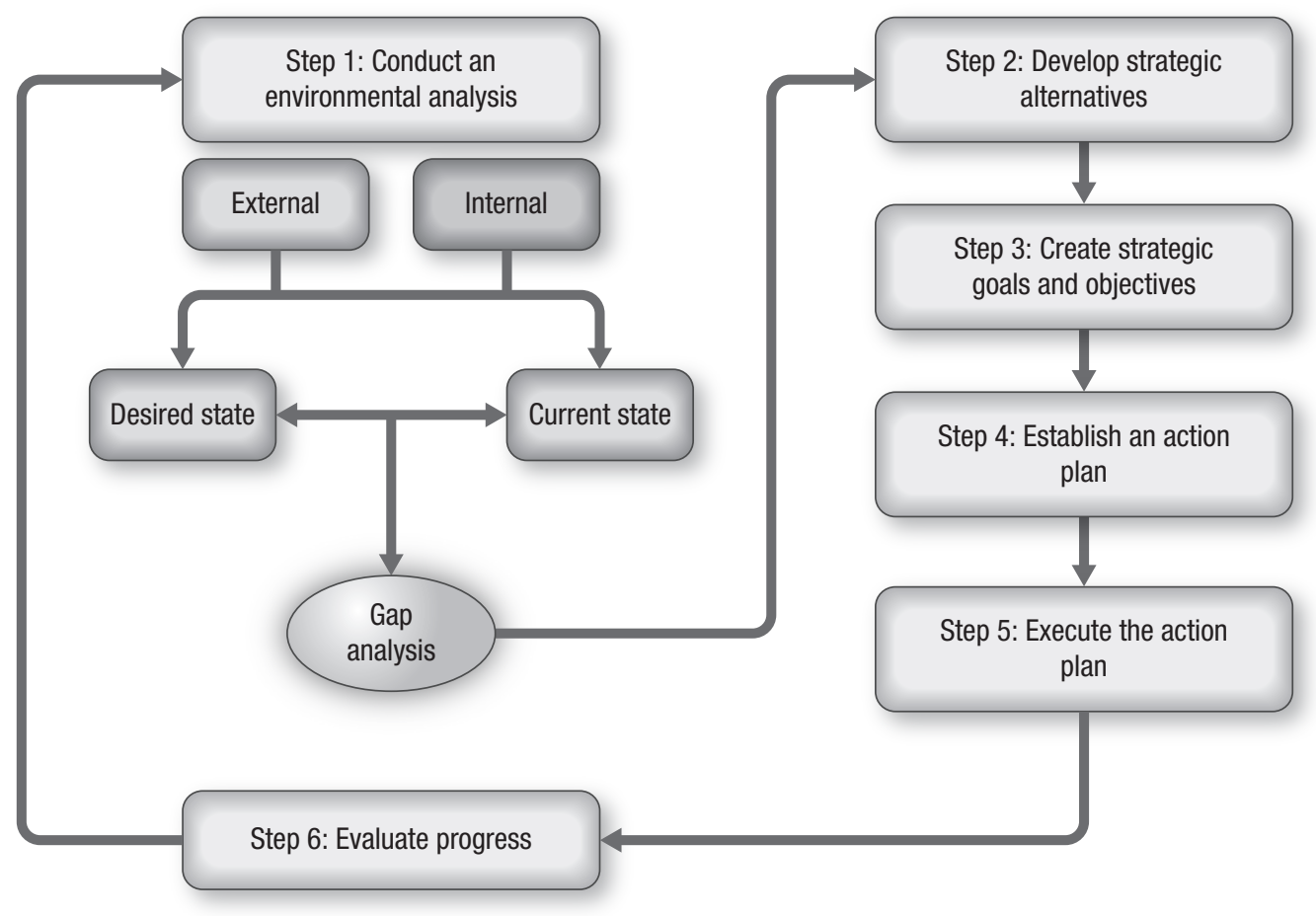

FIGURE 2.3 The steps to developing a strategic plan.

SOURCE: Adapted from Walston, S. L. (2013). Strategic healthcare management: Planning and execution. Health Administration Press

participation in the data gathering and analysis process, and provides a platform on which to inform the creation of strategic options and decision-making. The data gathered through the environmental analysis create the underlying assumptions that drive the success of the planning process.

The environmental analysis is not a onetime process. Rather, organizations should develop a process for continual surveillance, interpretation, discussion, and the sharing of relevant findings on an ongoing basis. The data and information garnered from these analyses, both internal and external, are used to inform the development of new strategies as well as assess progress and identify opportunities in existing strategies.

\section{Internal Analysis}

The internal analysis is concerned with understanding the alignment of the strategic intent with organizational capabilities and competencies. Organizational capability is a broad term that defines the organization's capacity to "deploy resources that have been purposefully integrated to achieve the desired end state" and represent "the collective skills, abilities, and expertise of an organization" (Ulrich \& Smallwood, 2004). 
Capabilities, to include the ability to adapt or execute efficiently, are key intangible assets. According to Dave Ulrich and Norm Smallwood (2004), "you can't see or touch [capabilities], yet they can make all the difference in the world when it comes to market value, and are the outcome of investments in staffing, training, compensation, communication, and other human resources areas" (Ulrich \& Smallwood, 2004, p. 119).

Organizational competencies refer to the ability of an organization to achieve its purpose. Prahalad and Hamel (1990) coined the term core competence to distinguish those capabilities fundamental to an organization's performance and strategy-and those that provide it with a competitive advantage. Using the analogy of tree roots designed to give and propel growth, core competencies are "the collective learning in the organization," according to Prahalad and Hamel (1990, p. 81).

Conducting an internal analysis, the well-managed ambulatory practice seeks to understand current capabilities and competencies as well as consider what may be needed in the future. The internal analysis incorporates resource availability, allocation, and use. Resources include people, facilities, technology, equipment, and finances.

Data collected from the internal assessment after analysis and validation are used for an internal gap analysis. The internal gap analysis answers questions about the current and future state: Where are we now, and where do we need to be to achieve our chosen results? As gaps are identified, the organization must be prepared to reallocate existing resources or invest in new resources to close the identified gaps. For example, if the practice's desire to develop a population health management strategy includes the creation of a nurse contact center focused on ambulatory health promotion and the internal assessment reveals there is no capability or competencies within the organization related to this new venture, a gap has been identified. The gap in capability and competencies can be filled through the hiring of new talent (i.e., a senior nurse leader with contact center experience), developing talents in existing personnel (i.e., recruiting nurses from other areas in the practice and training them in ambulatory health promotion), or accessing sought-after skills through alliances or partnerships with people (i.e., a population health consultant) or organizations possessing the requisite competencies (i.e., create a joint venture with an existing nurse contact center). Considerations will also need to be given to additional gaps identified: How will data be collected and reported? Is additional technology needed to support the contact center? These gaps in people, facilities, technology, equipment, and finances will need to be identified and addressed for the plan to be successful.

Questions to consider related to the internal analysis include the following:

1. How does the organization bundle resources to build capabilities and core competencies that create value?

2. Could the organization align its resources in a better way to improve its capabilities and core competencies? 
3. Is it likely that environmental changes will make the organization's capabilities and core competencies obsolete?

4. Are substitutes for the organization's capabilities and core competencies available or soon to be available?

5. Could the organization's capabilities and core competencies easily be imitated?

6. How can the organization best protect or improve its capabilities and core competencies?

Leaders should continually assess and invest in building capabilities and core competencies in areas aligned with the organization's strategic intent.

Ambulatory practices should also be familiar with their internal data and historical trends. For example, is the volume of patients increasing or decreasing? Is the number of new patients growing as a percent of total encounters? What services are those new patients seeking? From which sources are referrals to the practice coming? Are certain referral sources increasing or decreasing the number of referrals to the practice? Are we able to schedule the referrals, or are we losing referrals? Comparing key practice data - by month, quarter, or year-may highlight areas of opportunity; Table 2.1 offers a list of elements that an ambulatory practice may evaluate to gain insight - and data that may offer a better understanding of the area of interest. This list is not exhaustive; every ambulatory practice should consider key data elements that can be tracked year over year and are meaningful to its strategic planning process.

\section{External Analysis}

The external analysis is focused on gathering intelligence on a host of factors related to the environment outside of the practice, including the competitive, regulatory, political, technological, and financial landscape.

There are several tools and techniques for completing an external assessment. These tools, which may also incorporate the internal analysis, include stakeholder analysis, SWOT (strengths, weaknesses, opportunities, and threats) analysis, PEST (political, economic, social, and technology) analysis, scenario analysis, financial analysis, portfolio analysis, and value-chain analysis (Walston, 2013, pp. 181-208). Each of these tools can prove valuable to an ambulatory practice; Figure 2.4 displays a sample PEST analysis for an ambulatory practice. These reliable strategic planning tools provide credible frameworks for the collection and analysis of both quantitative and qualitative data.

Hospitals report inpatient admission data, which are publicly available and easily accessible; however, obtaining market-based ambulatory data can be difficult. Claims data are available for Medicare outpatient services; other data may be purchased from third parties. However, the data may not be comprehensive or reflective of the ambulatory practice (particularly for a single-specialty practice), thus making 
TABLE 2.1 Elements for Evaluation in an Ambulatory Practice

\begin{tabular}{|l|l|}
\hline INSIGHT & DATA \\
\hline TALENT & $\begin{array}{l}\text { Average lead time to recruit by position; employee attrition rate by position; } \\
\text { the average tenure of employees (those who stay and those who leave); } \\
\text { employee engagement survey; exit interviews }\end{array}$ \\
\hline DEMAND & $\begin{array}{l}\text { Inbound referrals by specialty: referral sources, volume, turnaround time, and } \\
\text { leakage; CPT } \\
\text { (calls, chats, texts, messages) }\end{array}$ \\
\hline PRODUCTIVITY & $\begin{array}{l}\text { Encounters; work-relative value units, charges by clinician; clinic sessions } \\
\text { worked per year as compared to expected/contracted }\end{array}$ \\
\hline CAPACITY & $\begin{array}{l}\text { Total number of visits compared to industry standards by specialty; volume of } \\
\text { unused appointment slots; slot utilization; appointment no-show and last- } \\
\text { minute cancelation rate; clinician bump rate }\end{array}$ \\
\hline ACUITY & $\begin{array}{l}\text { Diagnosis codes; volume and frequency; evaluation and management code } \\
\text { levels }\end{array}$ \\
\hline MARKET & $\begin{array}{l}\text { Payer mix by site; percentage of physicians in the community by specialty; } \\
\text { appointment lag time for new patients by specialty }\end{array}$ \\
\hline OUALITY & $\begin{array}{l}\text { Patient-reported outcome measures; National Quality Forum measures } \\
\text { (process, cost/resource use, outcome, structure); payer performance related to } \\
\text { quality measures }\end{array}$ \\
\hline GROWTH & $\begin{array}{l}\text { Encounters; new patient encounters as a percentage of total encounters; } \\
\text { volume of new-to-practice patients ("net new") }\end{array}$ \\
\hline SATISFACTION & $\begin{array}{l}\text { Net Promoter Score; Clinician and Group Consumer Assessment of Healthcare } \\
\text { providers and Systems survey results over time; search engine ratings for }\end{array}$ \\
\hline
\end{tabular}

\begin{tabular}{|c|c|c|c|}
\hline Political & Economic & Social & Technology \\
\hline $\begin{array}{l}\text { Telemedicine regulations } \\
\text { uncertain }\end{array}$ & $\begin{array}{l}\text { Growing unemployment in } \\
\text { community leading to }\end{array}$ & $\begin{array}{l}\text { Heightened patient } \\
\text { expectations for sevice, }\end{array}$ & $\begin{array}{l}\text { Opportunity to expand } \\
\text { virtual care offerings }\end{array}$ \\
\hline Physician referral law & rising uninsured rates & access, and convenience & Expanding access to social \\
\hline $\begin{array}{l}\text { Medicaid expansion at the } \\
\text { state level }\end{array}$ & $\begin{array}{l}\text { Largest employer closing in } \\
\text { short term ( 1 year); }\end{array}$ & $\begin{array}{l}\text { High bad debt } \\
\text { Average age of community }\end{array}$ & $\begin{array}{l}\text { determinants of health } \\
\text { data }\end{array}$ \\
\hline Stable local governement & potential shift in payer mix & increasing ( $\sim 55$ YOA); & Integration of artificial \\
\hline $\begin{array}{l}\text { Provider-friendly insurance } \\
\text { commissioner elected for } \\
\text { coming term; may combat } \\
\text { trends in slow payments; } \\
\text { denials }\end{array}$ & $\begin{array}{l}\text { Economic growth in } \\
\text { adjacent markets, but } \\
\text { primary markets in decline } \\
\text { Low inflation rates }\end{array}$ & $\begin{array}{l}\text { pediatric population } \\
\text { decreasing } \\
\text { Growing need for mental } \\
\text { health }\end{array}$ & $\begin{array}{l}\text { intelligence in } \\
\text { administrative processes }\end{array}$ \\
\hline & $\begin{array}{l}\text { Shortage in labor markets } \\
\text { for medical assistants }\end{array}$ & & \\
\hline
\end{tabular}

FIGURE 2.4 Sample ambulatory practice PEST analysis. 
it directional at best. How then can the ambulatory practice obtain reliable and valid data on the external environment?

One way to conduct an environmental analysis is to identify and evaluate market trends that impact or influence the ambulatory practice. For example, an obstetrics and gynecology practice may review birth rates in its local market. Are the number of births in the area decreasing, flat, or increasing? These data are accessible, and when reviewed in conjunction with trends in practice volume, the collective data may signal an increase or decrease in practice market share.

Ambulatory practices can stay abreast of external trends is by joining and participating in professional associations. Meetings of state medical associations, national special societies, local coalitions of practice managers, or other groups may highlight trends that may impact the operations of the practice and offer networking opportunities that allow intelligence to be shared among members. Finally, the ambulatory practice administrator can run a simple keyword search on "trends in ambulatory care." The search can be customized to a specific date range, providing the most relevant news and articles to the strategic planning period.

As previously discussed, obtaining stakeholder input is essential. Reviewing patient or referring physician satisfaction survey data or organizing focus groups with select patients or key referral sources are ways to collect these data. If conducting a focus group, consider using a trained facilitator who can help guide the discussion and summarize the key takeaways.

Similar to the internal analysis, the results of the external analysis provide the basis for comparison between the current state and the desired state. Where gaps are identified, the organization must be committed to closing the identified gaps.

\section{Step 2: Develop Strategic Alternatives}

Once the environmental analysis is complete, it is time to consider the strategic alternatives. To this point, we have treated the environmental analysis as a singular event, when, in fact, it is an iterative process. Once the strategic plan is in place, regularly reassessing the environment and looking for gaps is part of the cyclical nature of the strategic planning process.

Let's consider an example related to the growth of an orthopedic practice. Our external analysis has revealed that the local government is building a new recreational center to attract local, regional, and national sports teams as part of its tourism strategy. The practice treats sports injuries but does not have a physician, advanced practice provider, or personnel specifically trained in sports medicine. How should the orthopedic practice respond?

- Work with local government officials to determine opportunities. What investments would the community be willing to make to support this 
aspect of their tourism strategy? Does the governing board have an existing relationship with community leaders that can offer insight into specific community needs and expectations? What are the expectations of the local government as it relates to healthcare for the new recreational center? Will it be choosing a preferred medical provider for the facility, or will the teams be selecting their own?

- Build the internal capability to meet this potential new demand. Does the practice have providers interested in sports medicine? If not, should the practice acquire this expertise either through recruitment or additional training by existing personnel? Are there providers in the market who could be recruited to fulfill this need? Should the practice invest in personnel such as athletic trainers or ancillaries related to the service such as mobile imaging? Are these services reimbursed? How many personnel would need to be recruited or acquired to be effective? What is the return on investment? What other capability should the practice develop to engage with the recreational center?

- Develop affiliation or partnership agreements with other providers to offer the full continuum of services. Should the practice partner with an external provider or facility to offer medical, training, therapy, imaging, and/or rehabilitation services? Are there alternative relationships that may serve the purpose of fulfilling this opportunity?

- Merge with another practice that already has existing sports medicine expertise. Does the practice have the interest but lack the capacity or resources to meet this new demand? Could a merger with another practice fulfill this opportunity-and perhaps others? How would the merged practices collaborate to meet this need? What identified gaps can merging the two practices resolve? How would the merged practices complement one another to address specific needs such as same-day access, weekend, evening, and emergent hours? Could there be a greater benefit (than simply the recreational center) for a merger?

- Do nothing. If the practice does not react, what, if any, is the expected response from competitors regarding the opportunity? Will the recreational center pursue opportunities outside of the local market if the needs are not fulfilled by the practice or a competitor in the market? If so, what are the implications of these activities?

There may be additional options for the practice to consider. Each of the possible strategic alternatives needs to be evaluated thoroughly. The alternatives should also be assessed against the organization's strategic intent. Which alternative allows the practice to fulfill its mission and vision? Does the chosen strategic alternative align with its values? Each alternative should be vetted by key stakeholders to ensure their views and opinions are heard. The alternatives should also be considered in light of 
regulatory, financial, and resource requirements. How will this impact other projects? Do we have the time and resources to pursue this option given other opportunities being considered? Can we afford not to pursue this opportunity? What changes should be considered in the existing strategic plan to take advantage of this potential new strategy? Finally, the competitive landscape is crucial to examine; if we decide not to pursue the opportunity, who will? What are the implications of a competitor engaging with the recreation center opportunity?

Once the strategic alternative is selected, the next step is to create the goals and objectives that will be used to guide execution.

\section{Step 3: Create Strategic Goals and Objectives}

In this phase of the planning process, the strategic alternative has been selected. Let us assume that the decision is made to merge with another orthopedic practice to build the resources and capacity to meet this potential new demand, take advantage of other opportunities related to growth in the orthopedic market, and prevent competitors from entering the market. The governing bodies of both practices, in this example, may become the managing physician partners of the newly merged practice. The managing partners direct the practice administrator from each practice to form a planning committee, composed of key providers and personnel, to develop a merger plan. Within this complex process, for simplicity in this example, the groups elect to focus on the following key areas through a phased approach: creating an organizational hierarchy, integrating staff payroll and benefit plans, and establishing a unified set of policies and procedures. For each area of focus, goals, and objectives need to be determined. The goals and objectives should follow the SMART principles for goal setting: specific, measurable, attainable, relevant, and time-bound.

\section{Step 4: Establish an Action Plan}

The action plan consists of specific tasks that must be accomplished to achieve the objectives. Furthermore, it is critical to establish accountability by identifying the persons who will be held responsible for executing each task. A project plan can facilitate the documentation of the progress steps, accountable individual(s), time frame, and assessment metric(s) for each task. Considering the execution of each task is essential.

For the orthopedic practice engaged in the merger as an example, communication regarding the organizational change is essential, but the timing of the announcement must be considered. The practice does not want to communicate too soon to prompt a competitive response from another individual or organization; however, neither does the practice want to risk the ill will of providers, staff, patients, and stakeholders by communicating too late. In sum, communication must be managed. Therefore, an 


\section{BOX 2.1 RECOMMENDATIONS FOR THE EXECUTION OF A STRATEGIC PLAN}

1. Keep it simple, and make it concrete

2. Debate assumptions, not forecasts

3. Use a rigorous framework, and speak a common language

4. Discuss resource deployments early

5. Concisely identify priorities

6. Continuously monitor performance

7. Reward and develop execution capabilities

SOURCE: Adapted from Mankins, M., \& Steele, R. (2005, July/August). Turning great strategy into great performance. Harvard Business Review, 83(7/8), 64-72.

action item would be "develop a thoughtful, appropriate communication plan that provides key messaging to providers, staff, patients, and stakeholders." Within the action plan will be milestones that need to be achieved, accompanied by when and who is responsible for ensuring the completion. Performance metrics will also be implemented to measure success.

\section{Step 5: Execute the Action Plan}

A strategy is guaranteed to fail without effective execution. Is it better to have a lackluster strategy that is expertly executed, or a thoughtful strategy that is executed poorly? Not having a clearly articulated, evidence-informed strategy places organizations at significant risk. However, having a deliberate, relevant strategy is also no guarantee of success. Effective execution is essential. Organizations typically realize only a portion of their strategies' potential value because of breakdowns in planning and implementation. The strategy-to-performance gap was recognized by management experts Mankins and Steele (2005), who offered recommendations in Box 2.1 to enhance the likelihood of the successful execution of a strategic plan.

Among organizations with a clearly defined strategy, many do not produce the desired change. These failures are in part due to missteps in execution. There are other factors associated with this performance, including challenges related to leadership, communication, decision-making, accountability, and an understanding of the organization's readiness and capacity for change.

Successful strategic planning requires deliberate oversight by the governing body and accountability by the leaders responsible for development and implementation. Without a plan or accountability for results, actions may be misdirected or lack the precision and focus needed for successful execution. 


\section{Step 6: Evaluate Progress}

Once the strategic plan's execution is underway, the planning cycle reverts to the reflection phase. This step, which is better considered an iterative process, involves collecting data on performance, monitoring progress along the charted course, and making adjustments as needed to keep the practice heading toward the ultimate desired outcome. Practices use a variety of instruments to monitor performance. Some practices use a RASCI (responsible, accountable, support, consulted, and informed) tool to assign a responsible party to a specific objective. Other practices may create a dashboard or a balanced scorecard that measures the completion of strategic objectives using a visual cue such as red, yellow, and green coloring to denote progress. A performance monitoring instrument provides a framework for managing the implementation of strategy, focusing attention on the importance of the strategy by all stakeholders.

Whichever tool is chosen, it should be simple to use, easy to understand, and provide a status summary that can be shared with practice providers, staff, and stakeholders at regular intervals.

Achieving the desired objectives and tactics is essential to a successful plan. Equally important, however, is a plan that can be modified and adapted due to a change in the internal or external environment. This is where feedback and learning become important. The data collected may be used to make adjustments. Stakeholders should be rewarded for the application of evidence as they seek to improve performance. Regular communication using a consistent tool ensures that strategic planning is an ongoing, iterative process rather than a single event.

\section{FUTURES WHEEL}

Most ambulatory practices engage in some type of strategic planning, whether it may be planning for a new service line, upgrading new software, or assessing the impact of competition. Plans are formulated to adapt and respond to a change in the internal or external environment. Traditional strategic planning, carefully prepared and monitored, can yield performance improvements. Practices may opt to enhance their strategic planning efforts by engaging in a process called "strategic foresight." The six steps included in strategic foresight include framing, scanning, forecasting, visioning, planning, and acting (Hines \& Bishop, 2015). Strategic foresight takes a deeper look at issues or challenges facing the ambulatory practice. The technique provides a framework for the ambulatory practice to develop and choose among several possible future strategic alternatives.

One tool used in strategic foresight is the "futures wheel." Invented in 1972 by Jerome C. Glenn, the futures wheel visually displays primary, secondary, and tertiary 


\section{FUTURES WHEEL: INCREASING WELLNESS VISITS}

To enhance preventive health for its patient population, an academic family practice division used the futures wheel exercise. The aim was to increase wellness visits to Medicare patients, a key preventive service provided to patients in the division's ambulatory practice. While traditional planning yielded some improvements, the division struggled to meet its budgeted targets for these important preventive maintenance visits. To date, outreach efforts to schedule Medicare patients for wellness visits had been largely met with refusal, cancelation, or no-shows. To gain further insight into how to increase Medicare wellness visits, the division's leadership brought together physicians, nurses, and supervisors, led by a trained facilitator, to brainstorm alternatives using a Futures Wheel. Medicare wellness visits were placed at the center of the wheel as the problem or issue needing attention. Using an expanded PEST Analysis by gathering and assessing the STEEPLE (social, technology, economic, environmental, political, legal, and ethical) criteria, the facilitator led the division's representatives through a brainstorming exercise to identify the primary and secondary impact of each factor on the wellness visits. During the brainstorming session, the practice was encouraged to shout out all ideas or suggestions. For example, while discussing social factors impacting the wellness visits, the group discussed that patients' unfamiliarity with the purpose of the visits led to a secondary impact of appointment no-shows, cancelations, or refusal. Another direct social impact was the provider culture, which generated little support for visits among staff. The practice brainstormed direct and indirect impacts for all of the STEEPLE criteria. The futures wheel (see Figure 2.5) provided a comprehensive view of direct (first-order) and indirect (second-order) factors impacting wellness visits. The futures wheel was then posted in the department so that all providers and staff could continue to brainstorm potential impacts. Subsequent division meetings used the information to develop action plans.

consequences of events, trends, emerging issues, and future potential alternatives (Glenn, 2009). A futures wheel also identifies various strategic alternatives and gives the end-user insight into the impact of choosing one strategic alternative over another (see the sidebar Futures Wheel: Increasing Wellness Visits for an example of using the futures wheel). While traditional strategic planning provides the well-managed ambulatory practice with a specific road map, strategic foresight provides the practice with several potential strategic alternatives. Flexibility and adaptability give the ambulatory practice an even greater opportunity for success in today's fast-paced healthcare industry.

\section{LEADERSHIP}

Leadership plays an essential role in the development of the strategic plan and ensuring its success in furthering the practice's strategic intent. Each strategy within a 


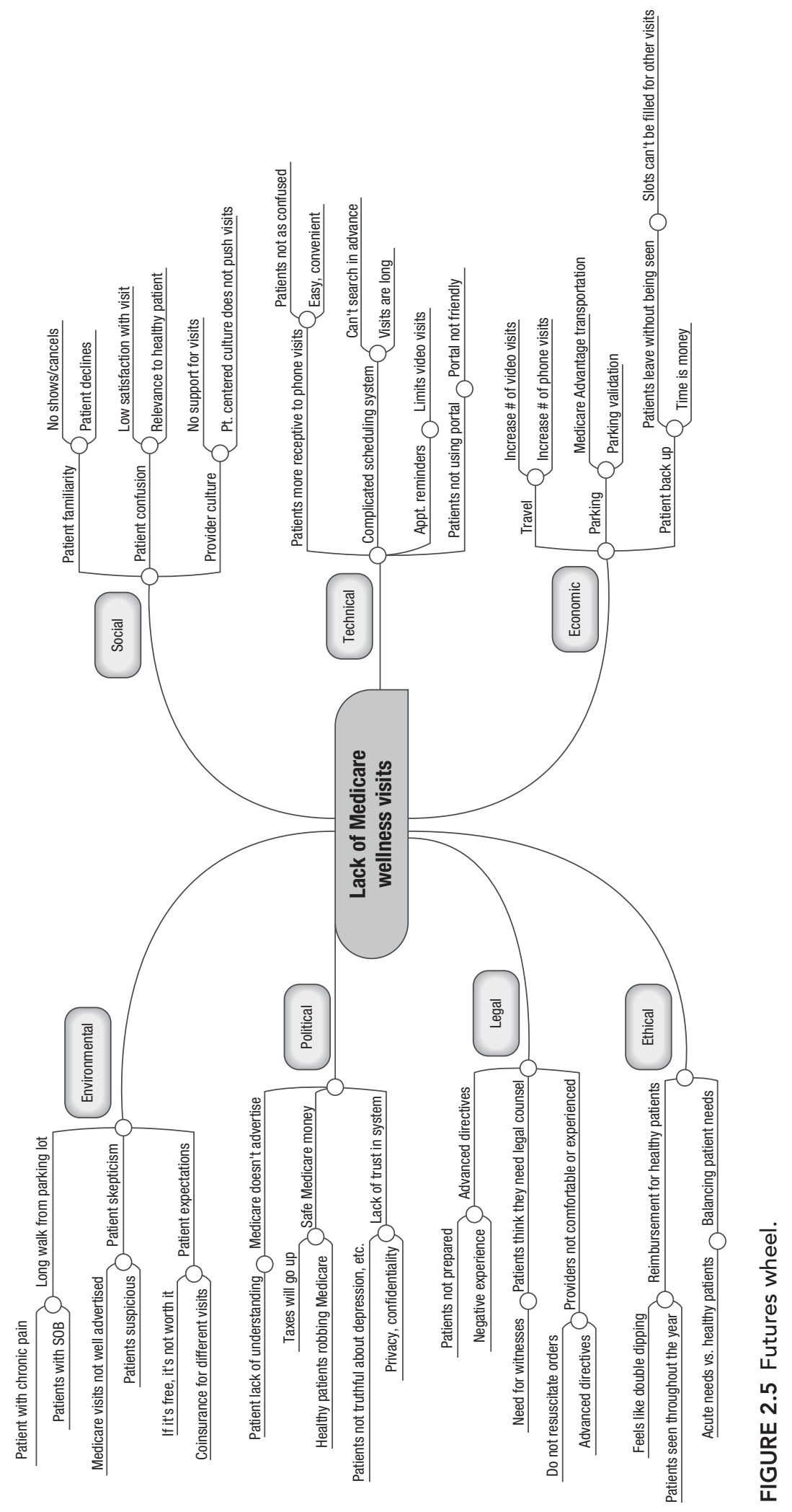


strategic plan provides a framework for action, much like the studs and joists used to frame a building. Leadership is like the roof, holding the building together and making it sustainable. The well-managed ambulatory practice engages leaders at all levels, formal and informal, in the strategic planning process.

Formal leadership roles vary in the ambulatory practice depending on the organization. For example, in large hospital settings, a medical director of ambulatory services may provide executive oversight for the ambulatory enterprise in concert with a vice president of ambulatory services. Together, these individuals form a leadership dyad that may be replicated throughout the ambulatory organization. The primary care service line, for example, may have the same dyad with a medical director and administrator; the leadership model may be duplicated in other service lines such as oncology, musculoskeletal, and cardiac care. In other ambulatory practices, the formal leader may be the physician founder or owner. Alternatively, the governing board may hire a practice administrator who is responsible not only for the strategy of the practice but also for the daily operations.

\section{Roles and Responsibilities}

The particulars of the organizational structure are not as important as having a clear understanding of the roles and responsibilities of each member of the leadership team along with a dedication to good communication, respect for each other's expertise, and an understanding and commitment to the organization's strategic intent. One of the most critical jobs of the leadership team is engaging providers and staff who will be implementing the proposed strategy. It is the leader's responsibility to build a process that allows everyone's input to be heard. For example, clinicians engaged in direct patient care bring valuable insight regarding the clinical processes of care delivery and can also represent the voices of their patients. For ambulatory practices, the perspectives of clinicians are especially meaningful given the heterogeneity of the ambulatory sector. In choosing among strategic alternatives, it is also critically important that ambulatory leaders consider the diversity of their patients, staff, and stakeholders. If conducting a patient or employee focus group, ensure the group has representation from the population it serves.

Ambulatory leaders should also create psychological safety, which allows for the critical review and evaluation of proposed strategic alternatives. In a psychologically safe environment, people feel comfortable speaking and offering ideas and feedback without being criticized or punished (Edmondson \& Lei, 2014). Allowing for honest and candid feedback among strategic alternatives is essential to developing a strategic plan that engages providers and staff. In gathering responses, a leader should not assume silence is agreement. Instead, a process built through a survey or another form of anonymous feedback allows everyone an opportunity to provide input. Some practices may distribute a copy of the draft strategic plan to each provider and staff member, 
giving them ample time to reflect and comment on the strategy; other practices may post a copy of the strategy on an intranet site or key area in the practice to allow providers and staff to comment. Never underestimate the importance of communicating early and often with the practice's providers and staff.

Once the strategic alternatives are appropriately vetted and the decision to proceed along a given path is made, the leadership team is charged with developing the action plan and tactics along with a timeline for completion. Further, leaders must engage the support of the providers and staff to achieve the desired results.

\section{Strategic Planning Skills}

The practice leader may be a physician executive, a practice administrator, or a combination of the two. Regardless of the organizational structure, leading an ambulatory practice is challenging. Ambulatory practice leadership styles are as varied as the organizational structures within which they operate. For this chapter, the focus is on the key skills necessary for the leader during the strategic planning process (see the sidebar The Importance of Emotional Intelligence in Healthcare Leadership for the value of emotional intelligence). As it relates to strategic planning, the critical abilities of ambulatory practice leaders include the following:

1. Collaboration. The leader must collaborate with his or her physician colleague as part of the leadership dyad responsible for the strategic planning process. If no formal leadership dyad exists, the leader engages with informal physician leaders. Seek those physician leaders who are willing to provide honest feedback - and those who embrace change as well as representatives who are typically resistant. Engage personnel, as well as physicians. The strategic planning process should challenge the team to question the status quo and to brainstorm future strategic alternatives. Contesting the status quo- "how we have always done things" - may be uncomfortable for some providers and staff. However, if managed appropriately, the process may yield critical insights for strategic plan development and execution.

Conflict is inevitable as decisions are made regarding strategies, tactics, and actions; it can create negative feelings that may derail the strategic planning process. A collaborative leader refocuses the conflict away from the negative emotions and toward the best interests of the practice and the patients it serves. Research suggests that more diverse teams produce better results (Ibarra \& Hansen, 2011). The collaborative leader recognizes the richness found in diversity, acknowledges the uncomfortableness, and leads the team forward by building transparency and trust in the process by being open and receptive to the dialogue.

2. Teambuilding. During the strategic planning process, the leader must ensure clarity regarding the roles and responsibilities of each stakeholder. To avoid duplication, team members must be clear on the roles they perform 
during the strategic planning process and the responsibilities others conduct (Levi \& Askay, 2020). A leader is also responsible for building group cohesion. Fostering group solidarity builds a sense of unity and connects the team members to the practice's strategic intent, as well as its strategic plan. Practices embarking on a strategic planning process should consider the strength of their team structure before the planning process begins and take proactive steps to increase cohesion through team-building activities.

3. Change Leadership. Behavior change impedes the implementation of new initiatives. Whether the alteration is something relatively straightforward, such as adding a new screening tool to the arrival process, or something far more complex, like implementing a new billing system, persuading practitioners to adopt new ways to work requires behavior modification. Change is difficult. Leaders use their influence to help others see the value in making the change. Leaders tell the story of why a change is necessary and how it may benefit the practice. Furthermore, leaders help individuals determine the role that they can play in facilitating change.

Physician leaders can serve as champions among physicians for the desired change. The physician champion serves as an early adopter, acting to role model the desired behaviors. Early adopters lead by example, demonstrating the benefits of the new system and serving as a resource to others as they adopt the new process. Early adopters also help identify and resolve unanticipated issues that may arise with the new process.

4. Focus. Leadership, as Peter Drucker said, is about doing the right thing; management is about doing things right (Drucker, 2000). Within an ambulatory practice, the lines between leadership and management are often blurred. Particularly for small practices, administrators may find themselves responsible not only for the development of a strategic plan but also for its execution. Physician leaders need to balance the demands of a busy clinical practice while also planning for the future. For successful strategic plan development and execution, ambulatory practice leaders need dedicated time to gather data, analyze, and reflect on the strategic alternatives. For the busy clinician serving in a leadership role, this may result in decreasing the number of clinic sessions for an interim period while the plan is being developed.

The practice leader must be decisive yet flexible, trustworthy, and ethical. The leader must be able to not only see the big picture but also pay attention to the details; to relate to the governing body, physicians, staff, and community leaders as well as patients. Each stakeholder group has unique perspectives and expectations of the practice. The practice leader must communicate the mission and vision of the practice while being a role model of the values. They must be a good listener and able to sort through the trivia while maintaining a focus on what is important. Keeping an eye on the future, the leader must achieve this while sustaining the viability of the current practice. 


\section{THE IMPORTANCE OF EMOTIONAL INTELLIGENCE IN HEALTHCARE LEADERSHIP}

\section{Rick Evans}

\section{Senior Vice President}

Patient Services \& Chief Experience Officer

New York-Presbyterian Hospital

New York, New York

When we think of leadership skills and competencies in healthcare, the list includes obvious choices: content expertise in the area of one's responsibilities, experience in leading teams, financial acumen, strategic planning prowess, project management ability, and others.

However, there is another set of skills that is sometimes overlooked (despite a lot of literature that supports it). That is emotional intelligence.

In more than 20 years in healthcare, I have seen leaders succeed and some fail at all levels, from managers and directors to senior-level administrators. In my experience, there is often a common thread that influences success or failure. That is whether a leader has emotional intelligence or not.

Emotional intelligence encompasses an array of abilities. First, it is connected to self-awareness. Does a leader have the ability to recognize and monitor their emotions? Are they conscious of their reactions to the situation around them? Conversely, can they "read the room" and effectively detect and respond to the reactions of others to them? Does a leader know what their trigger points might be? Self-awareness is needed for leaders to then have the ability to govern themselves in the workplace. This awareness is something that should evolve through experience and, quite honestly, often emerges from both our successes and failures.

Awareness is the foundation for another key aspect of emotional intelligence- - the ability to self-regulate. Self-regulation is how we maintain professionalism and collegiality in healthcare. It allows us to consciously choose what emotions we display and express in workplace settings. It drives our personal leadership presence and professional profile. Again, in my experience, this is a major factor in leaders I have seen fail-the inability to govern themselves and their interactions. The lack of this ability degrades relationships and the willingness of others to collaborate. All too often, leaders who cannot effectively regulate themselves end up isolated. This severely inhibits their ability to get things done or to collaborate successfully.

Emotional intelligence is not only a set of skills; it is also an orientation. Leaders with emotional intelligence know that relationships are the means to achieve objectives. They are the currency of leadership and achievement. Leaders who are oriented toward building relationships cultivate them through collaboration and work actively to maintain them 
in times of conflict. Emotional intelligence is also an orientation toward empathy. Empathy in leadership reflects a desire to understand the needs, goals, and situations of others with whom we need to work to succeed. It acknowledges the need to create "win/win" scenarios whenever possible. When people feel you care about them and their agendas, they are more likely to be there for you when you need them in return. I've often reflected in my career on the concept of "you reap what you sow." When you demonstrate empathy and build relationships at work, you most often get the same in return. The converse is also true.

Cultivating one's emotional intelligence-both the skills and the orientation-is a key ingredient to success. No amount of clinical or administrative expertise will yield true long-term success without it. And, in its absence, difficulties will always loom. This is true even more in healthcare. Healthcare is truly a team sport. The essence of healthcare is humans serving other humans. Building emotional intelligence in leaders is consonant with healthcare's very mission. Finally, it is good for business too!

\section{CONCLUSION}

In this chapter, we discussed the important role strategic planning plays in the well-managed ambulatory practice. Having a structured, data-driven strategic planning process provides the organization with the ability to reaffirm its strategic intent. Following a defined planning process, the organization can maintain a sense of situational awareness of both the internal and external environments, consider strategic alternatives, formulate strategic goals and objectives, establish and execute an action plan, and evaluate progress towards the desired outcomes. The strategic planning process as described provides the platform from which the well-managed ambulatory practice can grow and thrive.

\section{DISCUSSION QUESTIONS}

1. Why is strategic planning an important element to a well-managed ambulatory practice?

2. Describe potential pitfalls or challenges with each step of the strategic planning process that ambulatory practice leaders should consider. Propose ways to avoid or mitigate the impact of the challenges identified.

3. Describe the elements of a PEST analysis and how the results may inform the strategic planning process.

4. Explain the notion of organizational competencies and the relevance of this concept to building organizational capacity. 
5. Explain the purpose of the vision, mission, and values in the strategic planning process.

6. In reference to Figure 2.2, select any one of the pillars and discuss how it relates to the strategic intent of the ambulatory practice.

7. Explain why "do nothing" may be a viable strategic alternative when developing the list of strategic alternatives.

8. Of the four critical abilities of ambulatory practice leaders as it relates to strategy development (collaboration, team building, change leadership, and focus), select which ability you think is most important. Justify your choice.

\section{REFERENCES}

Drucker, P. F. (1994, September/October). The theory of the business. Harvard Business Review, 72(5), 95-104.

Drucker, P. F. (2000). The Essential Drucker: The best of sixty years of Peter Drucker's essential writings on management. Routledge.

Edmondson, A. C., \& Lei, Z. (2014). Psychological safety: The history, renaissance, and future of an interpersonal construct. Annual Review of Organizational Psychology and Organizational Behavior, 1(1), 23-43.

Glenn, J. C. (2009). Futures wheel, futures research methodology version 3.0. Millennium Project. Hines, A., \& Bishop, P. (2015). Thinking about the future: Guidelines for strategic foresight. HPB.

Ibarra, H., \& Hansen, M. T. (2011). Are you a collaborative leader? Harvard Business Review, 89(78), 68-74, 164.

Levi, D., \& Askay, D. (2020). Group dynamics for teams (6th ed.) Sage.

Mankins, M., \& Steele, R. (2005, July/August). Turning great strategy into great performance. Harvard Business Review, 83(7/8), 64-72.

Orlikoff, J. E., \& Totten, M. K. (2006, July). Strategic planning: Maximizing the Board's impact. Trustee, 59(7), 15-20.

Prahalad, C. K., \& Hamel, G. (1990). The core competence of the corporation. Harvard Business Review, 68(3), 79-91.

Ulrich, D., \& Smallwood, N. (2004, June). Capitalizing on capabilities. Harvard Business Review, 82(6), 119-127.

Walston, S. L. (2013). Strategic healthcare management: Planning and execution. Health Administration Press. 